\title{
Whole-Genome Sequencing of a Clinically Isolated Antibiotic-Resistant Enterococcus faecium EntfacYE
}

\author{
Yara Elahi $^{1}$ iD, Golshid Javdani Shahedin² ${ }^{\text {D }}$, Ahmad Nejati ${ }^{\text {ID }}$, Iradj Ashrafi ${ }^{4}$ D, \\ Mahla Asadian 5 iD, Ramin Mazaheri Nezhad Fard 5* iD
}

\author{
1. Department of Genetics, Faculty of Life Sciences, Islamic Azad University Tehran North Branch, Tehran, Iran \\ 2. Pasteur Institute of Iran, Tehran, Iran \\ 3. Department of Virology, School of Public Health, Tehran University of Medical Sciences, Tehran, Iran \\ 4. Faculty of Veterinary Medicine, University of Tehran, Tehran, Iran \\ 5. Department of Pathobiology, School of Public Health, Tehran University of Medical Sciences, Tehran, Iran
}

10.30699/ijmm.15.6.692

\begin{abstract}
Background and Aim: Enterococcal infections are considered the most common nosocomial infections. Nowadays, enterococci show high resistance to common antibiotics, especially vancomycin. Vancomycin-resistant Enterococcus faecium is one of the most common nosocomial infections, which is included in the World Health Organization priority pathogens list for research and development of new antibiotics. In this case, we focused on the E. faecium EntfacYE genome and its antibiotic-resistant genes to understand the reasons that caused this bacteria to be resistant to antibiotics.
\end{abstract}

Materials and Methods: In total, 25 enterococcal samples were isolated from patients' blood. Bacteriophages were isolated on a multidrug-resistant Enterococcus faecium EntfacYE in our previous study. In this study, the isolated E. faecium EntfacYE strain was verified using Sanger partial sequencing of the bacterial elongation factor Tu. EntfacYE strain was assessed for antibiotic resistance, and the bacterial genome was extracted and completely sequenced. The sequenced genome was analyzed, and the genes were annotated in the DNA Data Bank of Japan.

Results: Totally, EntfacYE genome subsystems included 23 various categories with 59 genes belonging to antimicrobial resistance genes, such a way that 49 antibiotic resistance genes were included in specific subsystems, while ten genes lacked specific subsystems. Moreover, cadmium, cobalt, copper, zinc, and mercury resistance genes were identified in the EntfacYE genome.

Conclusion: In conclusion, studies on bacterial genomes help researchers to identify characteristics of common pathogens, including virulence and antibiotic-resistance genes, and hence better understand bacterial pathogenesis to provide novel solutions for the treatment of common infections.

Keywords: Antibiotic resistance, Clinical sample, Enterococcus faecium, Whole-genome Sequencing

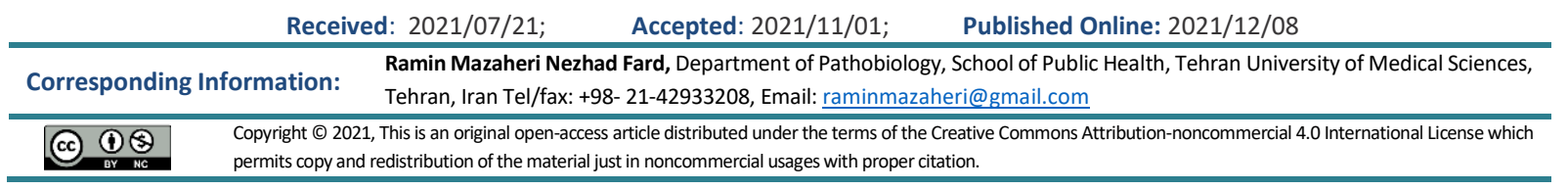

Use your device to scan and read the article online

Elahi Y, Javdani Shahedin G, Nejati A, Ashrafi I, Asadian M, Mazaheri Nezhad Fard R. Whole-Genome Sequencing of a Clinically Isolated Antibiotic-Resistant Enterococcus faecium EntfacYE. Iran J Med Microbiol. 2021; 15 (6) :692-699

Download citation: BibTeX | RIS | EndNote | Medlars | ProCite | Reference Manager | RefWorks
Send citation to:
$\otimes$ Mendeley
2 Zotero
Hif RefWorks

\section{Introduction}

Enterococci are Gram-positive catalase-negative bacteria that are naturally present in the gastrointestinal tract (GIT) of humans, animals, and the environment. Enterococci were reported to be the leading cause of antibiotic-resistant infections in the human bloodstream, urinary tract (UI), and surgical wounds in the 1970s and 1980s. Antibiotic resistance is a major threat to human health worldwide and significantly increases health care costs (1). Two important and pathogenic species of enterococci are E. faecium and E. faecalis. Enterococcus faecium as a human pathogen is particularly important due to its 
high resistance to various antimicrobial drugs such as ampicillin and vancomycin (2). In general, up to $80 \%$ of E. faecium isolates in hospitals are resistant to vancomycin (3). The rapid spread of vancomycin resistance in these strains greatly challenges the ability of physicians to treat infections as no other antimicrobial drugs are often available (4).

Accurate identification of vancomycin-resistant enterococci (VRE) reservoirs and transmission pathways is critical for strategic infection control interventions $(5,6)$. For example, enterococci could transmit vancomycin resistance to methicillin-resistant Staphylococcus aureus (MRSA) (7). Whole-genome sequencing (WGS) is a comprehensive high-resolution method used to sequence a wide range of bacterial species and mapping of pathogen trans-mission routes (8). Enterococcus faecium genetic features have been investigated specifically to identify the bacterial lineages (9). Factors associated with E. faecium infections in humans include virulence factors (VF), antibiotic resistance (AR) genes, mobile genetic elements (MGE), and multiple-locus sequencing (MLST) patterns $(10,11)$. The aim of this study was to sequence and analyze the multidrug-resistant $E$. faecium EntfacYE genome, focusing on the genes involved in antibiotic resistance.

\section{Material and Methods}

\section{Isolation of $E$. faecium EntfacYE}

Twenty-five clinical enterococci were isolated from patients' blood from 2019 to 2020. Sampling was carried out in a university teaching hospital, Tehran, Iran (ethics approval no. IR.TUMS.SPH.REC.1397.139). Of all the enterococcal isolates, one $E$. faecium strain isolated from a clinical blood sample that three various bacteriophages were isolated on it, was selected in this study (E. faecium EntfacYE) (12). The bacterial strain was cultured on trypticase soy agar (TSA) media for purification. Furthermore, the isolate was verified using morphological, biochemical, and molecular techniques. Assays such as Gram staining, catalase, growth in $6.5 \% \mathrm{NaCl}$, and glucose utilization were used for the isolate as well.

Furthermore, the isolates were assessed for resistance to common antibiotics using the disk diffusion method. The isolate was cultured on MuellerHinton agar media and exposed to the selected antibiotics at $37^{\circ} \mathrm{C}$ for $24 \mathrm{~h}$. The assessed antibiotics included cefoxitin, ceftriaxone, clindamycin, erythromycin, linezolid, and vancomycin. After incubation, inhibition zone diameters were measured, and a bacterial resistance pattern was reported.

\section{Sanger Partial Sequencing}

Molecular identification of the isolate was carried out using PCR amplification of the elongation factor Tu
(EF-Tu) gene. Then, a PCR amplicon was sequenced using the Sanger method (Kawsar Biotech, Iran). Briefly, a single bacterial colony was dissolved in sterile distilled water (DW) in a sterile microtube. To extract the bacterial genome, the microtube was incubated at $90^{\circ} \mathrm{C}$ for $30 \mathrm{~min}$ and then centrifuged at $7500 \mathrm{~g}$ for $5 \mathrm{~min}$. The genome concentration was measured, and the ratios of 260/280 and 260/230 nm were calculated using NanoDrop One (Thermo Fisher Scientific, USA). Then, the extracted bacterial genome was amplified using a pair of specific primers, including Ent1: 5'-TACTGACAAACCATTCATGATG-3' and Ent2: 5'-AACTTCGTCACCAACGCGAAC-3' (13).

Enterococcus faecium EntfacYE Genome Analysis

The E. faecium EntfacYE genome was extracted using ethanol and propanol (precipitation method). Then, the extracted genome was wholely sequenced using Illumina Hiseq platform (Novogene, China) and de novo genome assembly as well as SPAdes algorithm. The bacterial genome was comprehensively analyzed using RAST (rapid annotation using subsystem technology) online sequence analysis service (https://rast.nmpdr.org).

\section{Results}

In general, the phenotypic assessment results verified the enterococcal isolate as E. faecium. To genotypically verify the isolates, the bacterial tuf gene was partially sequenced and the results were annotated in the DDBJ (DNA Data Bank of Japan) genomic database (accession Nos. LC580430 and LC580431) after primary analysis with BLAST (basic local alignment search tool) online service (https://blast.ncbi.nlm.nih.gov). Then, the bacterial whole genome sequence was analyzed, and the genome structure and subsystems were studied (Table 1). The bacterial whole-genome sequencing results were also annotated in DDBJ (BOPS 01000001BOPS 01001574). EntfacYE genome subsystems included 23 various categories. In general, carbohydrates, amino acids, and protein metabolism categories included the most-frequent and sulfur metabolism, cell division and cell cycle, and phosphorus metabolism categories included the least-frequent subsystems in the EntfacYE genome. Antimicrobial resistance assessment results revealed resistance of $E$. faecium EntfacYE to vancomycin, erythromycin, clindamycin, cefoxitin, and ceftriaxone. Antibiotic resistance genes were divided into two major groups of genes with and without subsystems. Relatively, 49 antibiotic resistance genes were included in specific subsystems, while ten genes lacked specific subsystems (Tables 2 and $\underline{3}$ ). Furthermore, cadmium, cobalt, copper, zinc, and mercury resistance genes were identified. 
Table 1. General information about E. faecium EntfacYE genome sequencing analysis*

Genome Annotation/Feature

DDBJ accession nos.

Isolation source

Size (bp)

GC content (\%)

Contig

Subsystems

CDS

RNAs
E. faecium EntfacYE

BOPS01000001-BOPS01001574

Patient blood sample

$3,624,552$

39

1

242

3957

71

*: https://getentry.ddbj.nig.ac.jp/getentry/

Table 2. Antimicrobial-resistance subsystems in E. faecium EntfacYE genome analysis*

\begin{tabular}{|c|c|c|}
\hline No. & Subsystem & Feature \\
\hline 1 & Copper homeostasis & Negative transcriptional regulator-copper transport operon \\
\hline 7 & Copper homeostasis & Copper-translocating P-type ATPase \\
\hline 1 & Copper homeostasis & Copper chaperone \\
\hline 1 & Copper homeostasis & Copper tolerance protein \\
\hline 2 & Bile hydrolysis & Choloylglycine hydrolase \\
\hline 1 & Cobalt-zinc-cadmium resistance & Cobalt-zinc-cadmium resistance protein \\
\hline 1 & Cobalt-zinc-cadmium resistance & Probable cadmium-transporting ATPase \\
\hline 2 & Cobalt-zinc-cadmium resistance & Transcriptional regulator, MerR family \\
\hline 2 & Mercuric reductase & $\begin{array}{l}\text { PF00070 family, FAD-dependent NAD(P)-disulfide } \\
\text { oxidoreductase }\end{array}$ \\
\hline 2 & Mercuric reductase & Mercuric ion reductase \\
\hline 2 & Mercury resistance operon & Mercuric ion reductase \\
\hline 1 & Vancomycin tolerance locus & Sensor histidine kinase $\mathrm{VncS}$ \\
\hline 2 & Vancomycin tolerance locus & $A B C$ transporter, ATP-binding protein Vex 2 \\
\hline 1 & Vancomycin tolerance locus & Two-component response regulator $\mathrm{VncR}$ \\
\hline 1 & Vancomycin tolerance locus & $\begin{array}{l}\text { ABC transporter membrane-spanning permease, Pep export, } \\
\qquad \text { Vex1 }\end{array}$ \\
\hline 1 & Vancomycin Tolerance Locus & $\begin{array}{l}\text { ABC transporter membrane-spanning permease, Pep export, } \\
\qquad \text { Vex3 }\end{array}$ \\
\hline 1 & Resistance to fluoroquinolones & DNA gyrase subunit B \\
\hline 1 & Resistance to fluoroquinolones & DNA gyrase subunit A \\
\hline 1 & Copper homeostasis: copper tolerance & Cytoplasmic copper homeostasis protein CutC \\
\hline 1 & Fosfomycin resistance & Fosfomycin resistance protein FosX \\
\hline 1 & Beta-lactamase & $\begin{array}{c}\text { Metal-dependent hydrolases of the beta-lactamase } \\
\text { superfamily I }\end{array}$ \\
\hline 1 & Cadmium resistance & Cadmium efflux system accessory protein \\
\hline 1 & Multidrug resistance efflux pumps & Multidrug resistance efflux pump PmrA \\
\hline 1 & Multidrug resistance efflux pumps & $\begin{array}{l}\text { Multiple antimicrobial extrusion protein }(\mathrm{Na}(+) / \text { drug } \\
\text { antiporter), MATE family of MDR efflux pumps }\end{array}$ \\
\hline 1 & $\begin{array}{l}\text { Mycobacterium virulence operon involved in } \\
\text { protein synthesis (SSU ribosomal proteins) }\end{array}$ & SSU ribosomal protein S7p \\
\hline
\end{tabular}




\begin{tabular}{|c|c|c|}
\hline No. & Subsystem & Feature \\
\hline 1 & $\begin{array}{l}\text { Mycobacterium virulence operon involved in } \\
\text { protein synthesis (SSU ribosomal proteins) }\end{array}$ & Translation elongation factor $\mathrm{G}$ \\
\hline 2 & $\begin{array}{l}\text { Mycobacterium virulence operon involved in } \\
\text { protein synthesis (SSU ribosomal proteins) }\end{array}$ & Translation elongation factor Tu \\
\hline 1 & $\begin{array}{l}\text { Mycobacterium virulence operon involved in } \\
\text { protein synthesis (SSU ribosomal proteins) }\end{array}$ & SSU ribosomal protein $\mathrm{S} 12 \mathrm{p}$ \\
\hline 2 & $\begin{array}{l}\text { Mycobacterium virulence operon involved in DNA } \\
\text { transcription }\end{array}$ & DNA-directed RNA polymerase beta subunit \\
\hline 3 & $\begin{array}{l}\text { Mycobacterium virulence operon involved in DNA } \\
\text { transcription }\end{array}$ & DNA-directed RNA polymerase beta subunit \\
\hline 1 & $\begin{array}{l}\text { Mycobacterium virulence operon involved in } \\
\text { protein synthesis (LSU ribosomal proteins) }\end{array}$ & LSU ribosomal protein L35p \\
\hline 1 & $\begin{array}{l}\text { Mycobacterium virulence operon involved in } \\
\text { protein synthesis (LSU ribosomal proteins) }\end{array}$ & Translation initiation factor 3 \\
\hline 1 & $\begin{array}{l}\text { Mycobacterium virulence operon involved in } \\
\text { protein synthesis (LSU ribosomal proteins) }\end{array}$ & LSU ribosomal protein L20p \\
\hline
\end{tabular}

Table 3. Non-subsystem antimicrobial resistance genes in E. faecium EntfacYE genome*

\begin{tabular}{|c|c|c|c|}
\hline Type & $\begin{array}{l}\text { Length } \\
\text { (bp) }\end{array}$ & Subsystem & Function \\
\hline CDS & 531 & Uncharacterized & $\begin{array}{l}\text { Protein YacP, similar to C-terminal domain of ribosome protection-type Tc- } \\
\text { resistance proteins }\end{array}$ \\
\hline CDS & 372 & Uncharacterized & Glyoxalase/bleomycin resistance protein/dioxygenase superfamily protein \\
\hline CDS & 321 & Uncharacterized & Small multidrug resistance family (SMR) protein \\
\hline CDS & 1713 & Uncharacterized & $\begin{array}{l}\text { Heterodimeric efflux } A B C \text { transporter, multidrug resistance }=>L m r C \text { subunit of } \\
\qquad \mathrm{LmCD}\end{array}$ \\
\hline CDS & 1773 & Uncharacterized & $\begin{array}{l}\text { Heterodimeric efflux } A B C \text { transporter, multidrug resistance }=>\operatorname{LmrD} \text { subunit of } \\
\qquad \mathrm{Lm} C D\end{array}$ \\
\hline CDS & 1920 & Uncharacterized & Tetracycline resistance, ribosomal protection type $=>$ Tet(M) \\
\hline CDS & 900 & Uncharacterized & Cobalt/zinc/cadmium resistance protein CzcD \\
\hline CDS & 486 & Uncharacterized & Teicoplanin resistance protein VanZ \\
\hline CDS & 609 & Uncharacterized & $\begin{array}{c}\text { D-alanyl-D-alanine dipeptidase (EC 3.4.13.22) of vancomycin resistance }=> \\
\operatorname{VanX}\end{array}$ \\
\hline CDS & 969 & Uncharacterized & D-lactate dehydrogenase $\mathrm{VanH}$, associated with vancomycin resistance \\
\hline
\end{tabular}

*: $\underline{\text { https://rast.nmpdr.org/seedviewer.cgi?page=Organism\&organism=6666666.717700 }}$

\section{Discussion}

In recent decades, the resistance of most pathogens such as enterococci to available antibiotics has broadly increased. Enterococci cause a variety of infections, including opportunistic infections in hospitalized patients. In fact, E. faecium is one of the most important causes of nosocomial infections. Based on the reports, the mortality rate due to enterococcal bacteremia is estimated as $15-35 \%$ (14). In the present study, $23 \%$ of the bacterial genome was covered by subsystems, including various categories (Figure 1). The highest proportion was linked to the carbohydrates and protein metabolism groups, similar to a recent study on E. faecium R.A73 genome by Jeni et al. (2020) (15). Results from the present study demonstrated that the E. faecium EntfacYE strain isolated from a clinical blood sample was resistant to vancomycin, erythromycin, clindamycin, cefoxitin, and ceftriaxone and included various antibiotic-resistance genes. In recent decades, enterococcal resistance to vancomycin has increased, causing serious problems in treating infections $(16,17)$. In 2015, O'Toole et al. reported significant increases in vancomycin-resistant E. faecium isolates from Royal Hobart Hospital of Australia. Their study presented a shifting epidemicology pattern of VREfm from sporadic to endemic. They also showed the utility of isolates from asymptomatic patients to link epidemiological gaps between the patients (18). Lytsy et al. compared whole-genome sequences of vancomycin-resistant enterococci in three suspected outbreaks in Sweden 
during 2013-2015 using PFGE and MLST. They concluded that WGS-ANI was an easy method for this purpose. It was a user-friendly method, compared to
MLST and PFGE. They recommended using WGS-ANI instead of PFGE for epidemiological outbreak investigations (19).
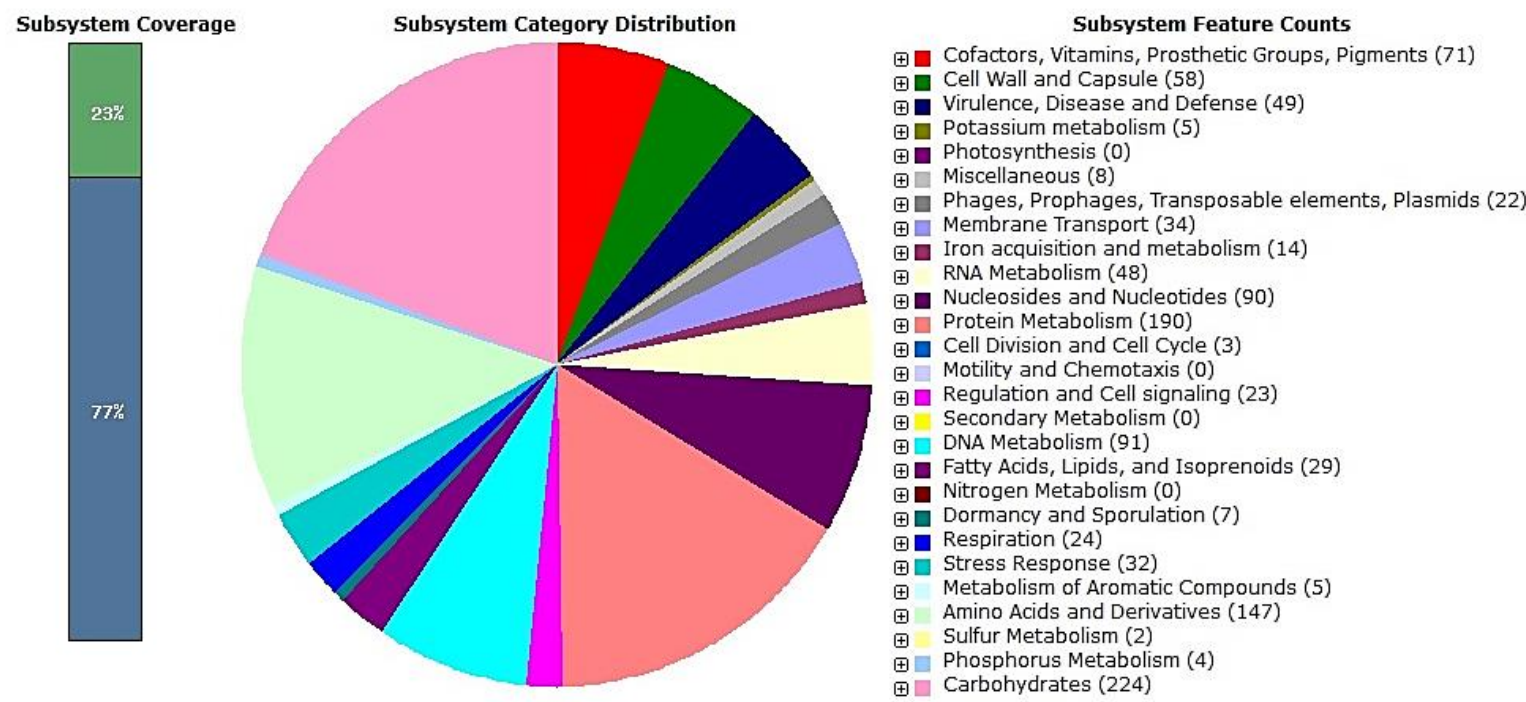

Figure 1. EntfacYE genome subsystem analysis using RAST

Based on the results from molecular studies, $E$. faecium is more resistant to routine antibiotics compared to $E$. faecalis, in which more than half of the enterococcal pathogens are resistant to common antibiotics such as vancomycin, ampicillin, and aminoglycosides (20). In this study, vancomycin resistance in EntfacYE isolate was due to the presence of van genes in the bacterial genome. A study in Iran showed that 12 out of $22 \mathrm{E}$. faecium isolates were resistant to vancomycin (21). In another study by Arbabi et al. (2016), more than half of E. faecium isolates were resistant to vancomycin (22). Active efflux pump is a common mechanism responsible for erythromycin resistance (23); thus, the presence of genes encoding efflux proteins in EntfacYE might lead to erythromycin resistance. In a study in Iran, $64 \%$ of enterococcal isolates, including $E$. faecalis and $E$. faecium, demonstrated resistance to erythromycin (24). Enterococci are intrinsically resistant to clindamycin; however, no relevant mechanisms have already been described (25). In this study, clindamycin resistance was associated with the $A B C$ protein family. In a study in 2020, two genes involved in clindamycin resistance were identified in Bacillus licheniformis and Bacillus paralicheniformis (26). In the current study, resistance to cefoxitin and ceftriaxone was due to the presence of beta-lactamase genes. In a study by Rengaraj et al. (2016), 49\% of S. aureus isolates were resistant to cefoxitin (27). In the present study, fosfomycin resistance genes were detected. This antibiotic is an alternative antibiotic against multi- drug-resistant bacteria (28). In a study on Pseudomonas stutzeri, Soltani et al. (2015) reported that soils contaminated with heavy metals were potential sources for isolating metal-resistant strains (29). As heavy metals' level increases in the environment due to modern industrial and agricultural activities, bacteria develop strategies to decrease intracellular concentrations of these toxic contaminants. Therefore, environments contaminated with heavy metals naturally contain microorganisms capable of resisting these metals (30). Plasmids mostly carry resistancerelated genes and could spread resistance genes between bacteria through MGEs (e.g., the spread of plasmid genes from cadmium-resistant bacteria to other bacteria). In fact, heavy metal resistance is often associated with plasmids. However, this resistance is sometimes chromosomally originated (31). Copper homeostasis subsystem in E. faecium EntfacYE was reported in Salmonella enterica and Mycobacterium tuberculosis in 2019 (32).

Furthermore, bile salt hydrolysis determinants in $E$. faecium EntfacYE were investigated in Enterococcus strains isolated from artisanal dairy products in a study by Nami et al. (2019) (33). The presence of heavy metal resistance genes such as copper-zinc, cadmium, and mercury in the bacterial genome could be due to the gene transfer through plasmids or other MGEs. Accurate identification of Enterococcus species and their antibiotic resistance patterns is critical in providing effective treatments and appropriate medications $(28,34)$. 


\section{Conclusion}

In this study, E. faecium EntfacYE genome analysis was carried out, focusing on antimicrobial resistance encoding genes. Further analysis of bacterial genomes, especially antibiotic resistance genes, can open new horizons for discovering novel medications other than common antibiotics and efficiently prevent the further spread of bacterial resistance.

\section{Acknowledgment}

The authors thank all the staff within the Microbiology Laboratory, School of Public Health, Tehran University of Medical Sciences for their help.

\section{Funding}

None.

\section{Conflict of Interest}

The authors declared no conflict of interest.

\section{References}

1. Gilmore MS, Lebreton F, van Schaik W. Genomic transition of enterococci from gut commensals to leading causes of multidrug-resistant hospital infection in the antibiotic era. Curr Opin Microbiol. 2013;16(1):10-6. [PMID] [PMCID] [DOI:10.1016/j.mib.2013.01.006]

2. Willems RJ, Top J, Marga van Santen D, Coque TM, Baquero F, Grundmann H, Bonten MJ. Global spread of vancomycin-resistant Enterococcus faecium from distinct nosocomial genetic complex. Emerg Infect Dis. 2005;11(6):821.

[DOI:10.3201/1106.041204] [PMID] [PMCID]

3. Arias CA, Murray BE. Emergence and management of drug-resistant enterococcal infections. Expert Rev Anti Infect Ther. 2008;6(5) :637-55. [DOI:10.1586/14787210.6.5.637] [PMID]

4. Bonten MJ, Willems R, Weinstein RA. Vancomycin-resistant enterococci: why are they here and where do they come from? Lancet Infect Dis. 2001;1(5):314-25. [DOI:10.1016/S1473-3099(01)00145-1]

5. Benenson S, Cohen MJ, Block C, Stern S, Weiss $Y$, Moses AE, JIRMI Group. Vancomycin-resistant enterococci in long-term care facilities. Infect Control Hosp Epidemiol. 2009;30(8):786-9. [DOI:10.1086/598345] [PMID]

6. Gruber I, Heudorf U, Werner G, Pfeifer $Y$, Imirzalioglu C, Ackermann H, Brandt C, Besier S, Wichelhaus TA. Multidrug-resistant bacteria in geriatric clinics, nursing homes and ambulant care-prevalence and risk factors. Int J Med
Microbiol Suppl. 2013;303(8):405-9.

[DOI:10.1016/j.ijmm.2013.05.002] [PMID]

7. Kos VN, Desjardins CA, Griggs A, Cerqueira G, Van Tonder A, Holden MT, Godfrey P, Palmer KL, Bodi K, Mongodin EF, Wortman J. Comparative genomics of vancomycin-resistant Staphylococcus aureus strains and their positions within the clade most commonly associated with Methicillin-resistant S. aureus hospital-acquired infection in the United States. MBio. 2012;3(3). [DOI:10.1128/mBio.00112-12]

8. Brodrick HJ, Raven KE, Harrison EM, Blane B, Reuter S, Torok ME, Parkhill J, Peacock SJ. Wholegenome sequencing reveals transmission of vancomycin-resistant Enterococcus faecium in a healthcare network. Genome Med. 2016;8(1):19. [DOI:10.1186/s13073-015-0259-7] [PMID] [PMCID]

9. Kim EB, Marco ML. Nonclinical and clinical Enterococcus faecium strains, but not Enterococcus faecalis strains, have distinct structural and functional genomic features. Appl Environ Microbiol. 2014;80(1):154-65. [DOI:10.1128/AEM.03108-13] [PMID] [PMCID]

10. Arias CA, Murray BE. The rise of the Enterococcus: beyond vancomycin resistance. Nat Rev Microbiol. 2012;10(4):266-78. [DOI:10.1038/nrmicro2761] [PMID] [PMCID]

11. Palmer KL, Gilmore MS. Multidrug-resistant enterococci lack CRISPR-cas. MBio. 2010;1(4). [DOI:10.1128/mBio.00227-10] [PMID] [PMCID]

12. Elahi Y, Nowroozi J, Fard RM. Isolation and characterization of bacteriophages from wastewater sources on Enterococcus spp. isolated from clinical samples. Iran J Microbiol. 2021;13(5):671-7. [DOI:10.18502/ijm.v13i5.7434]

13. Adeniji OO, Sibanda T, Okoh Al. Recreational water quality status of the Kidd's Beach as determined by its physicochemical and bacteriological quality parameters. Heliyon. 2019;5(6):e01893. [PMID] [PMCID] [DOI:10.1016/i.helivon.2019.e01893]

14. Wang $Y$, Oppong TB, Liang X, Duan G, Yang $H$. Methicillin-resistant Staphylococcus aureus and vancomycin-resistant enterococci cocolonization in patients: A meta-analysis. Am J Infect Control. 2019;48(8):925-932. [DOI:10.1016/i.ajic.2019.11.010] [PMID]

15. El Jeni R, Ghedira K, El Bour M, Abdelhak S, Benkahla A, Bouhaouala-Zahar B. High-quality genome sequence assembly of R. A73 Enterococcus faecium isolated from freshwater 
fish mucus. BMC Microbiol. 2020;20(1):1-2. [DOI:10.1186/s12866-020-01980-8] [PMID] [PMCID]

16. Shokoohizadeh L, Ekrami A, Labibzadeh M, Ali L, Alavi SM. Antimicrobial resistance patterns and virulence factors of enterococci isolates in hospitalized burn patients. BMC Research Notes. 2018;11(1):1-5. [DOI:10.1186/s13104-017-30885] [PMID] [PMCID]

17. Hosseini MJ, Sadripour R. Antibiotic resistance pattern of bacteria isolated from nosocomial infection in internal surgery and neurosurgery intensive care unit (NICU) at a tertiary care hospital in Tehran, Iran. Biosci Biotechnol Res Asia. 2017;14(3):1095-102.

[DOI:10.13005/bbra/2547]

18. Leong KW, Cooley LA, Anderson TL, Gautam SS, McEwan B, Wells A, Wilson F, Hughson L, O'Toole RF. Emergence of vancomycin-resistant Enterococcus faecium at an Australian hospital: a whole genome sequencing analysis. Sci Rep. 2018;8(1):1-1. [DOI:10.1038/s41598-018-246146] [PMID] [PMCID]

19. Lytsy B, Engstrand L, Gustafsson $\AA$, Kaden R. Time to review the gold standard for genotyping vancomycin-resistant enterococci in epidemiology: comparing whole-genome sequencing with PFGE and MLST in three suspected outbreaks in Sweden during 20132015. Infect Genet Evol. 2017;54:74-80. [DOI:10.1016/j.meegid.2017.06.010] [PMID]

20. Akpaka PE, Kissoon S, Jayaratne P, Wilson C, Golding GR, Nicholson AM, Lewis DB, Hermelijn SM, Wilson-Pearson A, Smith A. Genetic characteristics and molecular epidemiology of vancomycin-resistant enterococci isolates from Caribbean countries. PloS One. 2017;12(10) :e0185920. [PMID] [PMCID]

[DOI:10.1371/journal.pone.0185920]

21. Shahraki S, Rabi Nezhad Mousavi M. Determination of virulence factors in clinical multidrug resistance enterococci isolates at southeast of Iran. Jundishapur J Microbiol. 2017;10(5). [DOI:10.5812/ijm.45514]

22. Arbabi L, Boustanshenas $M$, Rahbar $M$, Owlia $P$, Adabi M, Koohi SR, Afshar M, Fathizadeh S, Majidpour A, Talebi-Taher M. Antibiotic susceptibility pattern and virulence genes in Enterococcus spp. isolated from clinical samples of Milad hospital of Tehran, Iran. Arch Clin Infect Dis. 2016;11(3). [DOl:10.5812/archcid.36260]

23. Seppälä $H$, Skurnik $M$, Soini $H$, Roberts $M C$, Huovinen P. A novel erythromycin resistance methylase gene (ermTR) in Streptococcus pyogenes. Antimicrob Agents Chemother. 1998;42(2):257-62. [DOl:10.1128/AAC.42.2.257] [PMID] [PMCID]

24. Ahmadpoor N, Ahmadrajabi R, Esfahani S, Hojabri Z, Moshafi MH, Saffari F. High-level resistance to erythromycin and tetracycline and dissemination of resistance determinants among clinical enterococci in Kerman-Iran. Med Princ Pract. 2021; Mar 31. Online ahead of print. [DOI:10.1159/000516216] [PMID] [PMCID]

25. Kristich CJ, Rice LB, Arias CA. Enterococcal infection-treatment and antibiotic resistance. In: Enterococci: From commensals to leading causes of drug resistant infection. Boston: Massachusetts Eye and Ear Infirmary; 2014.

26. Jeong DW, Lee B, Heo S, Oh Y, Heo G, Lee JH. Two genes involved in clindamycin resistance of Bacillus licheniformis and Bacillus paralicheniformis identified by comparative genomic analysis. PloS One. 2020;15(4): e0231274. [DOI:10.1371/journal.pone.0231274] [PMID] [PMCID]

27. Rengaraj R, Mariappan S, Sekar U, Kamalanadhan A. Detection of vancomycin resistance among Enterococcus faecalis and Staphylococcus aureus. Journal of clinical and diagnostic research: JCDR. 2016;10(2):DC04. [PMID] [PMCID] [DOI:10.7860/JCDR/2016/17552.7201]

28. Zavaryani SM, Mirnejad R, Piranfar V, Moghaddam MM, Sajjadi $N$, Saeedi $S$. Assessment of susceptibility to five common antibiotics and their resistance pattern in clinical Enterococcus isolates. IJP. 2020;15(2):96. [DOI:10.30699/ijp.2020.114009.2236] [PMID] [PMCID]

29. Soltani Nezhad S, Rabbani Khorasgani M, Emtiazi G. Analysis of zinc resistance gene in zinc and zinc oxide nanoparticles resistant Pseudomonas stutzeri SEE-1 isolated from soil. JMW. 2015;8(23):139-47.

30. Guo H, Luo S, Chen L, Xiao X, Xi Q, Wei W, Zeng G, Liu C, Wan Y, Chen J, He Y. Bioremediation of heavy metals by growing hyperaccumulaor endophytic bacterium Bacillus sp. L14. Bioresour Technol. 2010;101(22):8599-605. [DOI:10.1016/j.biortech.2010.06.085] [PMID]

31. Shirdam R, Khanafari A, Tabatabaei A. Cadmium, nickel and vanadium accumulation by three strains of marine bacteria. Iran J Biotechnol. 2006;3(4):180-7.

32. Li C, Li Y, Ding C. The role of copper homeostasis at the host-pathogen axis: from bacteria to fungi. 
Int J Mol Sci. 2019;20(1):175.

[DOI:10.3390/ijms20010175] [PMID] [PMCID]

33. Nami $Y$, Vaseghi Bakhshayesh $R$, Mohammadzadeh Jalaly $H$, Lotfi $H$, Eslami S, Hejazi MA. Probiotic properties of Enterococcus isolated from artisanal dairy products. Front
Microbiol. 2019;10:300. [PMID] [PMCID] [DOI:10.3389/fmicb.2019.00300]

34. Lavova M, Bezekova J, Canigova M, Krocko M, Domig K. Species identification of enterococci by biochemical test and molecular-genetic methods. Potravinarstvo. 2014;8(1):124-9.

[DOI:10.5219/364] 